This item was submitted to Loughborough's Research Repository by the author.

Items in Figshare are protected by copyright, with all rights reserved, unless otherwise indicated.

\title{
Competing surface reactions limiting the performance of ion-sensitive field- effect transistors
}

PLEASE CITE THE PUBLISHED VERSION

http://dx.doi.org/10.1016/j.snb.2015.05.096

\section{PUBLISHER}

(c) Elsevier

VERSION

AM (Accepted Manuscript)

\section{PUBLISHER STATEMENT}

This work is made available according to the conditions of the Creative Commons Attribution-NonCommercialNoDerivatives 4.0 International (CC BY-NC-ND 4.0) licence. Full details of this licence are available at: https://creativecommons.org/licenses/by-nc-nd/4.0/

\section{LICENCE}

CC BY-NC-ND 4.0

\section{REPOSITORY RECORD}

Stoop, Ralph L., Mathias Wipf, Steffen Muller, Kristine Bedner, lain A. Wright, Colin J. Martin, Edwin C. Constable, et al.. 2019. "Competing Surface Reactions Limiting the Performance of lon-sensitive Field-effect Transistors". figshare. https://hdl.handle.net/2134/25449. 


\title{
Competing Surface Reactions Limiting the Performance of Ion-Sensitive Field-Effect Transistors
}

\author{
Ralph L. Stoop ${ }^{\mathrm{a}}$, Mathias Wipf ${ }^{\mathrm{a}}$, Steffen Müller ${ }^{\mathrm{b}}$, Kristine Bedner ${ }^{\mathrm{c}}$, Iain A. Wright ${ }^{\mathrm{b}}$, \\ Colin J. Martin ${ }^{\mathrm{b}}$, Edwin C. Constable ${ }^{\mathrm{b}}$, Wangyang Fu ${ }^{\mathrm{a}}$, Alexey Tarasov ${ }^{\mathrm{a}}$, Michel \\ Calame $^{\mathrm{a}}$, Christian Schönenberger ${ }^{\mathrm{a}}$ \\ ${ }^{a}$ Department of Physics, University of Basel, Klingelbergstrasse 82, 4056 Basel, Switzerland \\ ${ }^{b}$ Department of Chemistry, University of Basel, Spitalstrasse 51, 4056 Basel, Switzerland \\ ${ }^{c}$ Laboratory for Micro- and Nanotechnology, Paul Scherrer Institut, 5232 Villigen PSI, Switzerland
}

\begin{abstract}
Ion-sensitive field-effect transistors based on silicon nanowires are promising candidates for the detection of chemical and biochemical species. These devices have been established as $\mathrm{pH}$ sensors thanks to the large number of surface hydroxyl groups at the gate dielectrics which makes them intrinsically sensitive to protons. To specifically detect species other than protons, the sensor surface needs to be modified. However, the remaining hydroxyl groups after functionalization may still limit the sensor response to the targeted species. Here, we describe the influence of competing reactions on the measured response using a general site-binding model. We investigate the key features of the model with a real sensing example based on gold-coated nanoribbons functionalized with a self-assembled
\end{abstract}

${ }^{*}$ Correponding author at: Department of Physics, University of Basel, Klingelbergstrasse 82, 4056 Basel. Phone +41612673780

Email address: ralph.stoop@unibas.ch (Ralph L. Stoop) 
monolayer of calcium-sensitive molecules. We identify the residual $\mathrm{pH}$ response as the key parameter limiting the sensor response. The competing effect of $\mathrm{pH}$ or any other relevant reaction at the sensor surface has therefore to be included to quantitatively understand the sensor response and prevent misleading interpretations.

Keywords: ion-sensitive field-effect transistor, calcium sensing, site-binding model, competing surface reactions, gold-coated nanoribbons

\section{Introduction}

Since their introduction at the beginning of the 1970s[1], ion-sensitive field-effect transistors (ISFETs) have generated strong interest [2]. Their sensing principle is based on the gating effect induced by charged particles adsorbed at the sensor surface. Advances in micro- and nanofabrication have given the possibility to downscale the devices to the nanoscale.[3, 4] In particular, silicon nanowire FETs (SiNWFETs) have been used successfully for different sensing experiments. Although successful chemical sensing [5, 6, 7, 8, 9, 10, 11, label-free biosensing [12, ㅍ, 13, 4, 14, 15, 16, 17] and the recording of intracellular action potentials[18] have been demonstrated, the only commercial application is still pH sensing[3, 19, 20, 21, 22]. The reason for this development lies in the use of bare, high quality oxide surfaces such as $\mathrm{Al}_{2} \mathrm{O}_{3}$ or $\mathrm{HfO}_{2}$ which exhibit a high number of surface hydroxyl groups. In contact with the electrolyte, these groups are protonated or deprotonated, depending on the local $\mathrm{pH}$ at the surface as described 
by the site-binding model. [23, 24] The reaction builds up a net surface charge density $\sigma_{0}$ and surface potential $\Psi_{0}$ leading to a redistribution of the ions close to the surface described by the Boltzmann equation $p H_{s}=p H_{b}+e \Psi_{0} /(2.3 k T)$ with $p H_{b}$ being the bulk $\mathrm{pH}$ and $p H_{s}$ the surface $\mathrm{pH}, e$ the elementary charge, $k$ the Boltzmann constant and $T$ the absolute temperature. According to the Boltzmann equation, a change in bulk $\Delta p H_{b}$ can be compensated by both a change in surface $\Delta p H_{s}$ and a change in the surface potential $\Delta \Psi_{0}$, the latter being the measured quantity. The surface hydroxyl groups are effectively buffering the surface, leading to an almost constant $p H_{s}$. In this case, a change in bulk $\Delta p H_{b}$ is fully compensated by the surface potential and the so-called Nernstian response $\Delta \Psi_{0}=2.3 k T / e \Delta p H_{b}=59.5 \mathrm{mV} / \mathrm{pH}$ (at room temperature) is observed.

This intrinsic property of the gate dielectrics is important for the specific detection of proteins or ions other than protons.[25, 26, 27] For such sensing experiments, the oxide surface needs to be modified to specifically detect the targeted species. Besides ionselective membranes [28, 9], self-assembled monolayers (SAMs) of functional molecules have been used for this purpose. In the case of oxide surfaces, the self-assembly of silane monolayers has become a widely used method for functionalization [6, 3, 10, 17] in which surface hydroxyl groups are replaced by new functional groups. However, a certain number of hydroxyl groups will still remain on the surface. [29]

To understand the measured response of the sensor to changes in analyte concentra- 
tion, the influence of the remaining hydroxyl groups after functionalization has to be included. Wunderlich and co-workers demonstrated by an analytical description, that the sensitivity to protons can decrease or even suppress the measured signal for protein adsorption. [30]

In this work, we investigate the influence of $\mathrm{pH}$ on the specific detection of ionic species. We start with a simple general site-binding model explaining the influence of a competing reaction on the detection of a targeted species at the ISFET surface. The model assumes perfect selectivity of the surface sites and no competitive binding. It is, however, important to emphasize, that the reactions are still coupled via the surface potential. We show here that this coupling can lead to a full suppression of the response to the targeted species, in agreement with the results of Wunderlich et al. [30] We further demonstrate the key features of the model with a real physical sensing example implemented using goldcoated nanoribbon FETs functionalized by a SAM of calcium $\left(\mathrm{Ca}^{2+}\right)$ selective molecules. We find a moderate $\mathrm{pH}$ response of the bare gold surface of $\approx 30 \mathrm{mV} / \mathrm{pH}$ in the range from $\mathrm{pH} 3$ to $\mathrm{pH}$ 10, which indicates the presence of a small number of hydroxyl groups. The $\mathrm{pH}$ response remains unchanged after functionalization of the gold surface with the SAM. Hence, the number of hydroxyl groups is not affected by the functionalization[11] and the response to protons competes with the targeted $\mathrm{Ca}^{2+}$ adsorption as proposed by the model. 
To demonstrate the influence of these remaining hydroxyl groups, we measure the response to calcium ions in the physiologically relevant concentration range from $1 \mathrm{mM}$ to $1 \mathrm{M}$ in buffered solutions of $\mathrm{pH} 3, \mathrm{pH} 7$ and $\mathrm{pH} 10$. We find no response when measuring at $\mathrm{pH} 10$ whereas at $\mathrm{pH} 7$ and $\mathrm{pH} 3$, responses up to $20 \mathrm{mV} /$ dec were achieved. The measurements are in good agreement with the model and demonstrate the influence of the competing hydroxyl groups on the sensor response. Note that studies on the noise and sensitivity of this type of devices have been described in previous work. [29, 31, 32, 33.

\section{Theory}

In literature, two different approaches are commonly used to describe interfacial potentials, depending on whether charge adsorption is assumed to occur only at the solid surface or also within the material.[34, 35] The first approach is followed by the sitebinding model, frequently used to the describe the interface of ISFET devices with the solution. [23] In case of the site-binding model, the interface is assumed to be (ideally) polarized and therefore purely capacitive. The second model originates from the field of ion-selective electrodes and expands on the existence of a hydration layer within which charge adsorption occurs. [36] The corresponding interface is non-polarized and therefore a resistor in parallel to the capacitance has to be included. In this work, we focus on the site-binding model. This choice is further motivated in the supporting information. 
We first consider the simplest general case of two competing surface reactions, illustrated in Figure 1a. The system consists of a sensor exhibiting two different surface groups $\mathrm{L}_{1}$ and $\mathrm{L}_{2}$. The surface is in contact with the liquid containing only two singlycharged species, $\mathrm{A}_{1}^{+}$and $\mathrm{A}_{2}^{+}$. Both species can interact with the surface. We assume that $\mathrm{A}_{1}^{+}$specifically binds to $\mathrm{L}_{1}$ and $\mathrm{A}_{2}^{+}$specifically to $\mathrm{L}_{2}$, i.e. the system is orthogonal and we exclude any cross sensitivity. The resulting surface groups are either neutral $\left(\mathrm{L}_{1}()\right.$ and $\left.\mathrm{L}_{2}()\right)$ or positively charged upon analyte binding $\left(\mathrm{L}_{1}\left(\mathrm{~A}_{1}^{+}\right)\right.$and $\left.\mathrm{L}_{2}\left(\mathrm{~A}_{2}^{+}\right)\right)$. At chemical equilibrium the system can be described by

$$
\begin{aligned}
& \mathrm{L}_{1}\left(\mathrm{~A}_{1}^{+}\right) \rightleftharpoons \mathrm{L}_{1}()+\mathrm{A}_{1}^{+}, K_{1} \\
& \mathrm{~L}_{2}\left(\mathrm{~A}_{2}^{+}\right) \rightleftharpoons \mathrm{L}_{2}()+\mathrm{A}_{2}^{+}, K_{2} .
\end{aligned}
$$

$K_{1}$ and $K_{2}$ are the dissociation constants defined as

$$
\begin{aligned}
& K_{1}=\nu_{\mathrm{L}_{1}()} a_{1}^{\text {surface }} / \nu_{\mathrm{L}_{1}\left(\mathrm{~A}_{1}^{+}\right)} \\
& K_{2}=\nu_{\mathrm{L}_{2}()} a_{2}^{\text {surface }} / \nu_{\mathrm{L}_{2}\left(\mathrm{~A}_{2}^{+}\right)}
\end{aligned}
$$

with $\nu$ being the number of corresponding surface sites per unit area $\left(\mathrm{m}^{2}\right) . a_{1}^{\text {surface }}$ $\left(a_{2}^{\text {surface }}\right)$ is the activity of $\mathrm{A}_{1}^{+}\left(\mathrm{A}_{2}^{+}\right)$at the surface in mol/l $(\mathrm{M})$. In this model we identify one component, e.g. $\mathrm{L}_{2}$, as the intrinsic surface reactivity such as the reaction of protons with hydroxyl groups. In the following, we show that, although no cross sensitivity is assumed, the two reactions compete via the surface potential. For each type of surface 
groups $\mathrm{L}_{1}$ and $\mathrm{L}_{2}$, the total number of surface groups per unit area that can be either neutral or positively charged in this model, is given by $N_{1}$ and $N_{2}$ respectively:

$$
\begin{aligned}
& N_{1}=\nu_{\mathrm{L}_{1}()}+\nu_{\mathrm{L}_{1}\left(\mathrm{~A}_{1}^{+}\right)} \\
& N_{2}=\nu_{\mathrm{L}_{2}()}+\nu_{\mathrm{L}_{2}\left(\mathrm{~A}_{2}^{+}\right)} .
\end{aligned}
$$

The reactions with $\mathrm{A}_{1}^{+}$and $\mathrm{A}_{2}^{+}$lead to a surface charge density $\sigma_{0}$ given by the sum of the charged groups

$$
\sigma_{0}=e\left(\nu_{\mathrm{L}_{1}\left(\mathrm{~A}_{1}^{+}\right)}+\nu_{\mathrm{L}_{2}\left(\mathrm{~A}_{2}^{+}\right)}\right)
$$

with $e$ the elementary charge. The charged surface builds up a surface potential $\Psi_{0}$ which drops over the double layer capacitance $C_{d l}$ per unit area:

$$
\sigma_{0}=C_{d l} \Psi_{0}
$$

We approximate the double layer as a series connection of the Stern layer $C_{\text {Stern }}$ and the diffuse layer capacitance $C_{d i f}$ to $C_{d l}=C_{d i f} C_{\text {Stern }} /\left(C_{d i f}+C_{\text {Stern }}\right)$. An accepted value for the Stern layer capacitance is given by $C_{\text {Stern }}=0.2 \mathrm{Fm}^{-2}$. 20, 37] The diffuse double layer capacitance $C_{d i f}$ is estimated using the model of a simple parallel plate capacitor depending on the ionic strength of the analyte [29]. To keep the model as simple as possible, we assume a constant value of $C_{d i f}=0.7 \mathrm{Fm}^{-2}$, corresponding to an ionic strength of $100 \mathrm{mM}$. This results in a double layer capacitance of $C_{d l}=0.16 \mathrm{Fm}^{-2}$. A constant double layer is a good approximation for detection experiments in physiological solutions 
where high background salt concentrations are present because $C_{\text {Stern }}$ dominates in this case. Furthermore, taking the ionic dependence on the double layer into account does not change the mechanism of competing surface reactions. The assumption of a constant $C_{d l}$ is further discussed in the supporting information. The potential $\Psi_{0}$ established by the surface charge leads to a redistribution of the charged species $\mathrm{A}_{1}^{+}$and $\mathrm{A}_{2}^{+}$. The resulting surface activities of $\mathrm{A}_{1}^{+}$and $\mathrm{A}_{2}^{+}$can be related to the bulk activities $a_{1}$ for $\mathrm{A}_{1}^{+}$and $a_{2}$ for $\mathrm{A}_{2}^{+}$via the Boltzmann equation:

$$
a_{1}^{\text {surface }}=a_{1} e^{-e \Psi_{0} / k T} \text { and } a_{2}^{\text {surface }}=a_{2} e^{-e \Psi_{0} / k T} .
$$

Since the sensor signal is given by the surface potential $\Psi_{0}$, we are interested in solving the presented set of equations to obtain an expression for the surface potential as a function of the bulk activities $a_{1}, a_{2}$, the number of the surface sites $N_{1}, N_{2}$ and the dissociation constants $K_{1}$ and $K_{2}$. Inserting equation 5 in equation 4 yields $\Psi_{0}=e\left(\nu_{\mathrm{L}_{1}\left(\mathrm{~A}_{1}^{+}\right)}+\nu_{\mathrm{L}_{2}\left(\mathrm{~A}_{2}^{+}\right)}\right) / C_{d l}$. Both charged surface groups $\nu_{\mathrm{L}_{1}\left(\mathrm{~A}_{1}^{+}\right)}$and $\nu_{\mathrm{L}_{2}\left(\mathrm{~A}_{2}^{+}\right)}$can be calculated by inserting the two rate equations 2 in the corresponding equations for the total number of surface groups (equation 3) leading to $\nu_{\mathrm{L}_{1}\left(\mathrm{~A}_{1}^{+}\right)}=a_{1} N_{1} /\left(K_{1}+a_{1}\right)$ and $\nu_{\mathrm{L}_{2}\left(\mathrm{~A}_{2}^{+}\right)}=a_{2} N_{2} /\left(K_{2}+a_{2}\right)$. If we further include our assumption that both $A_{1}^{+}$and $A_{2}^{+}$follow a Boltzmann distribution, 
we obtain the following transcendental equation for $\Psi_{0}$

$$
\Psi_{0}=\frac{e N_{1}}{C_{d l}} \frac{a_{1}}{K_{1} e^{e \Psi_{0} / k T}+a_{1}}+\frac{e N_{2}}{C_{d l}} \frac{a_{2}}{K_{2} e^{e \Psi_{0} / k T}+a_{2}}
$$

where the first term of the sum is determined by the reaction between $A_{1}^{+}$and $\mathrm{L}_{1}$ and the second by the reaction between $\mathrm{A}_{2}^{+}$and $\mathrm{L}_{2}$. Although no analytical solution exists for $\Psi_{0}$, equation 7 can be used to determine analytical expressions for $a_{1}\left(\Psi_{0}, a_{2}\right)$ and $a_{2}\left(\Psi_{0}, a_{1}\right)$. In the following, we will use the latter expressions to calculate the activities $a_{1}$ and/or $a_{2}$ for a given $\Psi_{0}$. For illustrative reasons, we will plot the surface potential $\Psi_{0}$ always on the vertical and the activities $a_{1}$ and/or $a_{2}$ on the horizontal axis, suggesting that $\Psi_{0}\left(a_{1}, a_{2}\right)$ is the dependent variable, being a function of the bulk activities $a_{1}$ and $a_{2}$.

Figure $1 \mathrm{~b}$ shows the surface potential $\Psi_{0}$ versus activities $a_{1}$ and $a_{2}$ calculated for $K_{1}=10^{-5} \mathrm{M}, K_{2}=10^{-8} \mathrm{M}, N_{1}=0.8 \cdot 10^{17} \mathrm{~m}^{-2}, N_{2}=1.1 \cdot 10^{17} \mathrm{~m}^{-2}$ and $C_{d l}=0.16 \mathrm{Fm}^{-2}$. The values of $K_{1}$ and $K_{2}$ were chosen such as to correspond to typical values for binding constants assuming that the reaction involving $\mathrm{L}_{2}$ has a higher affinity compared to the other reaction. The densities of surface groups $N_{1}$ and $N_{2}$ are set to values corresponding to a typical gold surface as we will see in the results section. We observe a sigmoidal (or S-shape) response of the surface potential $\Psi_{0}$ upon changing the activity $a_{1}$ or $a_{2}$. In the four corners of the plot, a change in activity of $\mathrm{A}_{1}^{+}$or $\mathrm{A}_{2}^{+}$does not change the surface potential and hence detection is no longer possible. This is because the activities 
are either too small or the response is saturated, i.e. all the surface sites are already occupied. In between these boundaries, the surface potential is highly sensitive to changes in concentration of species $\mathrm{A}_{1}^{+}$and $\mathrm{A}_{2}^{+}$, which we will therefore call the region of maximum response, in $\mathrm{mV} /$ dec.

To better understand the relation between the surface potential and the two bulk activities we emphasize specific limits of the given system. We first focus on the targeted reaction involving species $\mathrm{A}_{1}^{+}$and neglect the influence of the competing reaction by setting $N_{2}=0$. The total potential shift due to the binding of the targeted species $\mathrm{A}_{1}^{+}$is then given by $\Delta_{t o t a l, a_{1}} \Psi_{0}=\Psi_{0}\left(a_{1} \rightarrow \infty\right)-\Psi_{0}\left(a_{1} \rightarrow 0\right)=e N_{1} / C_{d l}$. The region of maximum response depends on the dissociation constant $K_{1}$ for ligand $\mathrm{L}_{1}$. However, since we assume a Boltzmann distribution of the target analyte, the surface potential also strongly influences the binding. This is expressed by the term $K_{1} e^{e \Psi_{0} / k T}$ which is often called the effective binding constant. 38] For a particular value of $a_{1}$ and $\Psi_{0}$ such that the condition $a_{1}=K_{1} e^{e \Psi_{0} / k T}$ is fulfilled, half of the sites are bound to the analyte and half of the total potential shift is observed. Thus, the region of maximum response greatly depends on the surface potential.

If a competing reaction is present in the system $\left(N_{2} \neq 0\right)$, it will affect the surface potential in a similar way, which results in a nonlinear coupling between the two reactions. The strength of this coupling is given by the ratio $N_{2} / N_{1}$. This is shown in Figure 11c for 
$N_{1}=0.8 \cdot 10^{17} \mathrm{~m}^{-2}$ and a constant concentration of the competing species $a_{2}=1 \cdot 10^{-7} \mathrm{M}$. The detection of $a_{1}$ strongly suffers from the competing surface reaction if $N_{2}$ is two orders of magnitude larger than $N_{1}$. Suppressing the response to $a_{2}$ by reducing the number of surface sites $N_{2}$ leads to a continuous increase of the response to $a_{1}$ until the total potential shift of $80 \mathrm{mV}$ is achieved for $N_{2}=1 \cdot 10^{15} \mathrm{~m}^{-2}$. For increasing $N_{2}$, the response to a change in target analyte activity $a_{1}$ not only decreases, but also shifts towards higher $a_{1}$. This is expected, due to the dependence of the effective binding constant on the surface potential. The higher the surface potential, the more the response region shifts to higher activities. Any charge at the sensor surface will change the region of maximum response of the sensor. Finally, Figure 1 $1 \mathrm{~d}$ shows the response to $a_{2}$ for the same set of parameters at $a_{1}=10^{-15} \mathrm{M}$. As expected, the response increases with $\frac{N_{2}}{N_{1}}$ and the slope approaches the Nernst limit of $60 \mathrm{mV} / \operatorname{dec}$ for $N_{2}=1 \cdot 10^{19} \mathrm{~m}^{-2}$, showing in other words that if one ligand dominates, e.g. $\mathrm{L}_{2}\left(N_{2} \gg N_{1}\right)$ the surface responds strongly to $\mathrm{A}_{2}^{+}$but almost no response is possible for $\mathrm{A}_{1}^{+}$(see red curves in Figure 1 1 c,d).

\section{Material and Methods}

To underline the importance of a competing surface reaction, we functionalize goldcoated Si nanoribbon ISFETs with calcium-sensitive molecules and investigate the response to calcium ions in buffered solutions at different $\mathrm{pH}$. 
Device Fabrication. The samples were fabricated by a top-down approach on silicon on insulator (SOI) wafers (Soitec, France) with a buried oxide (BOX) layer of $145 \mathrm{~nm}$ thickness. A detailed description of the process can be found in our previous work. [33]. The $85 \mathrm{~nm}$ thick p-Si(100) device layer has a resistivity of $8.5-11.5 \Omega \mathrm{cm}$. A thermal oxide of $15 \mathrm{~nm}$ thick $\mathrm{SiO}_{2}$ was grown. To define the nanoribbon pattern, we used electron beam lithography (EBL). The structures were transferred to the wafer by dry etching of the $\mathrm{SiO}_{2}$ followed by an anisotropic wet etching of the $\mathrm{Si}$ device layer with tetramethylammonium hydroxide (TMAH and isopropyl alcohol 9:1 at 45 ). The resulting nanoribbons with Si (111) side faces have a length of $6 \mu \mathrm{m}$, a height of $80 \mathrm{~nm}$ and a width of $1 \mu \mathrm{m}$ or $25 \mu \mathrm{m}$. To achieve ohmic contact at the source and drain region, the corresponding areas were heavily doped by $\mathrm{BF}_{2}^{+}$ions (energy $=33 \mathrm{keV}$, dose $2.3 \times 10^{15} \mathrm{~cm}^{-2}$ ), followed by a thermal annealing step in a forming gas $\left(6 \mathrm{~min}\right.$ at $\left.950^{\circ} \mathrm{C}\right)$ to activate the dopants. To operate the devices in liquid, a thin protection layer of $22 \mathrm{~nm} \mathrm{Al}_{2} \mathrm{O}_{3}$ was deposited using atomic layer deposition (ALD) at $225^{\circ} \mathrm{C}$ (Savannah S100, Cambridge NanoTech). After opening the contact pads by etching with buffered hydrofluoric acid, the contact to the nanoribbon was completed by metallizing the contacts with $\mathrm{Al}-\mathrm{Si}(1 \%)$ and annealing at $450^{\circ}$. The good quality of the ALD oxide ensures low hysteresis and low leakage currents. In addition, $\mathrm{Al}_{2} \mathrm{O}_{3}$ surfaces are known to possess a high $\left(N_{s}=1 \cdot 10^{19} \mathrm{~m}^{-2}\right)$ number of hydroxyl groups leading to a Nernstian response of $59.5 \mathrm{mV} / \mathrm{pH}$ towards changes in proton 
concentration [29]. While this feature makes $\mathrm{Al}_{2} \mathrm{O}_{3}$ an ideal candidate for $\mathrm{pH}$ sensing, the high number of surface hydroxyl groups prevents detection of any other species as outlined in the last section. Therefore, the oxide surface was further covered by $5 \mathrm{~nm}$ chromium as adhesion layer and $20 \mathrm{~nm}$ gold by e-beam evaporation to substantially reduce the high response to $\mathrm{pH}$ intrinsic to the ALD oxide layer. The gold surface is then used as a platform for the functionalization with thiol-terminated functional molecules. The choice of gold as sensor surface is motivated by the fact that it allows to use well-established thiol-based chemistry for the self-assembly of functional molecules. It also enables the direct comparison with commericial tools based on surface plasmon resonance, such as the Biacore system (GE Healthcare). Furthermore, gold is a very stable material which allows operation at very harsh conditions such as $\mathrm{pH} 10$ or higher. Figure $2 \mathrm{a}$ shows the schematics of the device. To ensure leakage free operation in liquid, the sample was covered by an additional protection layer (SU-8 2002, MicroChem) with a thickness of $2 \mu \mathrm{m}$. Optical lithography was used to define openings in the SU-8 layer. After wire bonding the chip into a chip carrier, the bonds were finally sealed with epoxy (Epotek 353ND).

Microchannels. Microchannels fabricated in polydimethylsiloxane (PDMS, SYLGARD 184 Silicone Elastomer) were used to deliver the liquid to the nanoribbon surface. The channels were designed in SU-8 (SU-8 100 MicroChem) masters by EBL. Then, the masters were covered by liquid PDMS which was peeled-off from the wafer after curing at $60^{\circ} \mathrm{C}$ 
for $2 \mathrm{~h}$. Polytetrafluoroethylene (PTFE) tubes were used to connect the microchannels with the external fluidic system.

Surface Functionalization. The samples were cleaned in UV/Ozone (20 min) and closed with a PDMS microchannel. The sample is divided in two parts by the microchannel: One control channel and one for surface functionalization (active). The $\mathrm{Ca}^{2+}$-sensitive ligand was synthesized as described in the supporting information and dissolved in methanol $(\approx 2 \mathrm{mM})$. The active channel was then functionalized with the ligand by pumping the solution through the active microchannels with long stabilization intervals for $8 \mathrm{~h}$. After functionalization the channels were rinsed with methanol. Then, the active channel was flushed with aqueous ammonia (10\%) to remove the methyl esters for another $8 \mathrm{~h}$. Finally the active channel was rinsed with deionized water. As a result, we achieve a differential setup having both functionalized and control nanoribbons on the same device. Figure 2 a shows the schematics of a cross-section of a gold-coated nanoribbon after functionalization with the ligand.

Electrical Measurements in Liquid. $\mathrm{CaCl}_{2}$ ( $\geq 93.0 \%$, anhydrous, Sigma-Aldrich), $\mathrm{KCl}$ (ACS 99.0 - 100.5\%, Alfa Aesar) and NaF (ACS $\geq 99 \%$, Sigma-Aldrich) were dissolved in deionized water (resistivity $=18 \mathrm{M} \Omega \mathrm{cm})$ and buffered around $\mathrm{pH} 7$ with HEPES $(\approx$ $4 \mathrm{mM}$, AppliChem) and solution of $\mathrm{KOH}(\approx 1.5 \mathrm{mM}$, Merck $)$. For $\mathrm{CaCl}_{2}$-solutions around 
$\mathrm{pH} 3, \mathrm{HCl}\left(\approx 1.5 \mathrm{mM}\right.$, Sigma-Aldrich) was added to the buffered solution. For $\mathrm{CaCl}_{2}{ }^{-}$ solutions around $\mathrm{pH} 10, \mathrm{KOH}(\approx 2 \mathrm{mM})$ was added to the unbuffered solutions. For the $\mathrm{pH}$ measurement from $\mathrm{pH} 3$ to $\mathrm{pH} 10$, standard $\mathrm{pH}$ buffer solutions (Titrisol, Merck) were used. The exchange of the analyte solutions was achieved using a valve selector system (CHEMINERT VICI, Valco Instruments Co. Inc.) connected to a peristaltic pump (MCP, Ismatec). After stabilizing the sensor/electrolyte interface for $\approx 1 \mathrm{~h}$, a measurement series was started. During the measurement series, the exchange of the analyte was followed by a short, additional stabilization period of a few minutes. During a measurement, the transfer characteristics of the ISFET is recorded by sweeping the liquid potential, applied to the reference electrode, while measuring the current through the nanoribbon at constant source-drain voltage $V_{s d}=100 \mathrm{mV}$ (Keithley 2636A). Thanks to a switching box (Keithley 3706), up to 48 nanoribbons can be measured sequentially. A LabView program was used to control each device. To determine the response of each nanoribbon, we extract the corresponding threshold voltages $V_{t h}$ from the measured transfer characteristics (conductance $G$ versus liquid gate potential $V_{\text {ref }}$ ) as described in previous work. [11] The threshold voltage at the point of zero charge $V_{t h}(P Z C)$ can vary among different nanoribbons. However, we correlate a relative change in threshold voltage directly to a change in surface potential, for a p-type semiconductor this relation reads as $-\Delta \Psi_{0}=\Delta V_{t h}$. 


\section{Results and Discussion}

Figure 27 shows the schematics of an active nanoribbon ISFET after surface functionalization. The SAM of calcium-sensitive molecules leads to a new surface group ('Ligand'). The deprotonated carboxylic acid groups of the ligands have a high affinity towards calcium ions. Unlike in the general case, the groups resulting from the functionalization are negatively charged $\left(\operatorname{Ligand}()^{2-}\right)$ in the unbound state and become neutral upon $\mathrm{Ca}^{2+}$ binding (Ligand $\left.\left(\mathrm{Ca}^{2+}\right)\right)$. Besides the groups resulting from the functionalization, additional hydroxyl groups $(\mathrm{MOH})$ have to be assumed due to the residual $\mathrm{pH}$ response of gold. These hydroxyl groups can protonate or deprotonate leading to positively charged $\mathrm{MOH}_{2}^{+}$and negatively charged $\mathrm{MO}^{-}$besides the neutral $\mathrm{MOH}$ groups. Following the general model, the system can be described by three equilibrations:

$$
\begin{gathered}
\mathrm{MOH} \rightleftharpoons \mathrm{MO}^{-}+\mathrm{H}^{+}, K_{a} \\
\mathrm{MOH}_{2}^{+} \rightleftharpoons \mathrm{MOH}+\mathrm{H}^{+}, K_{b} \\
\text { Ligand }\left(\mathrm{Ca}^{2+}\right) \rightleftharpoons \operatorname{Ligand}()^{2-}+\mathrm{Ca}^{2+}, K_{\text {Ligand }} .
\end{gathered}
$$

$K_{a}, K_{b}$ and $K_{\text {Ligand }}$ are the dissociation constants and the total number of surface sites per unit area is $N_{s}=\nu_{\mathrm{MOH}_{2}^{+}}-\nu_{\mathrm{MO}^{-}}+\nu_{\mathrm{OH}}$ for the hydroxyl groups and $N_{\text {Ligand }}=$

$\nu_{\text {Ligand }()^{2-}}+\nu_{\text {Ligand }\left(\mathrm{Ca}^{2+}\right)}$ for the ligand. We assume that the charged ligands are located directly at the surface plane, which is a severe simplification of the electrostatic problem. In reality, the groups of the ligand will be distributed within a certain distance from the 
surface and additional electrostatic effects such as screening will be present. To keep the model as simple as possible, we neglect these effects. The qualitative influence of the competing reaction is independent thereof. The surface charge density is finally given by

$$
\sigma_{0}=e\left(\nu_{\mathrm{MOH}_{2}^{+}}-\nu_{\mathrm{MO}^{-}}-2 \nu_{\text {Ligand }()^{2-}}\right)=C_{d l} \Psi_{0}
$$

Including the Boltzmann distribution for both protons $\left(a_{H^{+}}^{\text {surface }}=a_{H^{+}} e^{-e \Psi_{0} / k T}\right)$ and calcium ions $\left(a_{\mathrm{Ca}^{2+}}^{\text {surface }}=a_{\mathrm{Ca}^{2+}} e^{-2 e \Psi_{0} / k T}\right)$ leads to

$$
\Psi_{0}=2 e \frac{N_{\text {Ligand }}}{C_{d l}}\left(\frac{a_{\mathrm{Ca}^{2+}}}{a_{\mathrm{Ca}^{2+}}+K_{\text {Ligand }} e^{2 e \Psi_{0} / k T}}-1\right)+e \frac{N_{s}}{C_{d l}} \frac{a_{\mathrm{H}^{+}}^{2}-K_{a} K_{b} e^{-2 e \Psi_{0} / k T}}{a_{\mathrm{H}^{+}}^{2}+a_{\mathrm{H}^{+}} K_{b} e^{e \Psi_{0} / k T}+K_{a} K_{b} e^{2 e \Psi_{0} / k T}},
$$

where the first term is due to the functionalized groups, the second term the intrinsic sensitivity to protons. Similar to the general case, equation 10 can be solved analytically for the bulk activities of protons $a_{H^{+}}$and calcium ions $a_{C a^{2+}}$.

After adapting the general model to the specific implementation with functionalized goldcoated nanoribbons, let us now turn to the experimental data. Figure $2 \mathrm{~b}$ shows the threshold voltage $V_{t h}$ of a functionalized (active) nanoribbon and a bare gold-coated (control) nanoribbon to changes in $\mathrm{pH}$. Both surfaces show a nearly linear response with a slope of $\approx 30 \mathrm{mV} /$ dec. $V_{t h}$ changes towards more positive values for increasing $\mathrm{pH}$, meaning that the surface becomes more negatively charged. The moderate sensitivity of the 
bare gold surface to $\mathrm{pH}$ has been explained by the formation of gold oxide. [11] Figure $2 \mathrm{~b}$ also shows that the functionalization does not change the response to $\mathrm{pH}$, in agreement with previous work.[11] Moreover, the deprotonated carboxylic acid of the ligand seems not to change the $\mathrm{pH}$ response either, due to its low pKa value $(<3)^{1}$. Both observations indicate that the number of surface hydroxyl groups responsible for the moderate $\mathrm{pH}$ response is not affected by the functionalization.

Figure 2 2 ,d,e show the $V_{t h}$ of the same pair of active and control devices for changing concentration of $\mathrm{CaCl}_{2}$, from $1 \mathrm{mM}$ to $1 \mathrm{M}$ at $\mathrm{pH} 3, \mathrm{pH} 7$ and $\mathrm{pH} 10$. Instead of the electrolyte concentration, we will now use the activity of the calcium ions $a_{\mathrm{Ca}^{2+}}$ on the horizontal axis. This allows the direct comparison of the measured data with the model. The activity is estimated using the standard Debye-Hückel approximation. [40] The control nanoribbons show a response to changes in $\mathrm{CaCl}_{2}$ concentration due to some unspecific adsorption of species of the electrolyte. To remove this background signal, we calculate the differential response, which is our sensor signal, given by $\Delta V_{t h}=V_{t h ; a c t i v e}-V_{t h ; c o n t r o l}$ and fit the data to the model. Fitting the differential response with the model is a simplification which we further justify in the supporting information.

\footnotetext{
${ }^{1}$ Similar functional groups show pKa values $<3$, see database compiled by R. Williams. 39]
} 
We use the $\mathrm{pH}$ measurement of three typical control nanoribbons as shown in Figure $3 \mathrm{a}$ to estimate the unknown parameters for the proton reactions $N_{s}, K_{a}, K_{b}$. In Figure 3a, the measured threshold voltage $V_{t h}$ of each nanoribbon has been converted to the surface potential via $\Psi_{0}=V_{t h}(P Z C)-V_{t h}$, where $V_{t h}(P Z C)$ is the threshold voltage at the assumed point of zero charge (PZC). This conversion is similar to previous work. [29, 41] We find that a point of zero charge between 6 and 7 gives a good fit with the data. We choose the set of parameters $K_{a}=10^{-8} \mathrm{M}, K_{b}=10^{-6} \mathrm{M}$ (leading to a $\mathrm{PZC}=7$ ) and $N_{s}=1.1 \cdot 10^{17} \mathrm{~m}^{-2}$ (black solid curves in Figure $3 \mathrm{a}$ ) which agrees well with the measured data. The dashed curves in Figure 3 a show curves plotted for different values of $K_{a}$ and $K_{b}$.

Figure $3 \mathrm{~b}$ shows the sensor response to $\mathrm{CaCl}_{2}$ (solid symbols) for three different $\mathrm{pH}$ values. Because calcium ions carry two charges $\left(\mathrm{Ca}^{2+}\right)$, the maximum possible (Nernstian) response to calcium is given by $29.8 \mathrm{mV} / \mathrm{dec}$. On the vertical axis of Figure 3b, the measured differential threshold voltage for each $\mathrm{pH}$ value $\Delta V_{t h}$ is converted to the surface potential using $\Psi_{0}=V_{\text {const }}-\Delta V_{\text {th }}$ where $V_{\text {const }}$ is a constant offset chosen such that the measurement points level with the theoretical surface potential. We find that at $\mathrm{pH} 10$, the response to calcium ions is already saturated at $a_{\mathrm{Ca}^{2+}}=1 \mathrm{mM}$ and the targeted ion cannot be detected. At $\mathrm{pH} 7$ and $\mathrm{pH} 3$, we find a clear response of $\approx 20 \mathrm{mV} / \mathrm{dec}$, which is two-thirds of the Nernstian response. $K_{\text {Ligand }}=50 \mathrm{M}$ and $N_{\text {Ligand }}=0.6 \cdot 10^{17} \mathrm{~m}^{-2}$ yields 
good agreement with the data for all $\mathrm{pH}$ values (solid curves). The dissociation constant is much higher than expected. [42] This can be attributed to additional electrostatic effects due to the charged ligand and the consequent distribution of the ions within the double layer. Furthermore, binding affinities may change after immobilization of the ligand on the surface (see supporting information).[43] Control measurements performed in $\mathrm{KCl}$ and NaF solution show no difference between active and control nanoribbons suggesting a high selectivity of the sensor to calcium ions (see supporting information).

We conclude this discussion with Figure $3 \mathrm{k}$, showing the calculated surface potential versus the activity of calcium ions $a_{\mathrm{Ca}^{2+}}$ and $\mathrm{pH}$ for the parameters obtained above. Clearly, the $\mathrm{pH}$ value determines both the total shift $\Delta \Psi_{t o t a l, a_{\mathrm{Ca}^{2+}}}$ and the region of maximum response. At high $\mathrm{pH}$, the surface potential is rather negatively charged which increases the activity of the calcium ions as given by the Boltzmann distribution. Hence, the response to $\mathrm{Ca}^{2+}$ saturates at lower concentrations compared to responses at lower $\mathrm{pH}$. It is important to note that any additional surface charge is directly changing the range in which the species can be detected. This can be used to tune the region of maximum response of the sensor. 


\section{Conclusions}

In conclusion, we propose a simple, general model to describe the influence of a competing surface reaction for specific detection experiments based on ISFETs. Although the model assumes perfect selectivity of the functionalization and excludes cross sensitivity in binding, up to full suppression to the targeted species can occur. This indirect interference of the competing reaction occurs via the surface potential: The liquid acts as a nonlinear feedback to the sensor response. The model describes the fundamental limits of the sensor response. Using $\mathrm{Ca}^{2+}$-sensitive receptor molecules on gold-coated nanoribbons, we demonstrate the influence of $\mathrm{pH}$ on the sensor response to calcium ions. The measured data is in good agreement with the model and a response of $20 \mathrm{mV} / \mathrm{dec}$ in the concentration range of $1 \mathrm{mM}$ up to $1 \mathrm{M}$ is achieved. We further demonstrate that the choice of material and functionalization is highly critical for the specific detection of species other than protons. Gold is an ideal candidate in this case because of its moderate $\mathrm{pH}$ response and the well-established protocols for the self-assembly of monolayers of functional molecules.

\section{Acknowledgements}

The authors gratefully acknowledge the support by the Swiss Nanoscience Institute (SNI), the Swiss Nano-Tera program, the European Commission under the FP7-NMP 
project Hysens (263091), the European Comission under the FP7-ICT project Symone (105244) and the Swiss National Science Foundation as part of the NCCR Molecular Systems Engineering. 


\section{References}

[1] P. Bergveld, Development of an ion-sensitive solid-state device for neurophysiological measurements, IEEE Trans. Biomed. Eng. BME-17 (1) (1970) 70-71. doi:10.1109/ TBME. 1970.4502688 .

[2] P. Bergveld, Thirty years of isfetology: What happened in the past 30 years and what may happen in the next 30 years, Sens. Actuators, B 88 (1) (2003) 1-20. doi:10.1016/S0925-4005(02)00301-5.

URL http://www.sciencedirect.com/science/article/pii/ S0925400502003015

[3] Y. Cui, Q. Wei, H. Park, C. M. Lieber, Nanowire nanosensors for highly sensitive and selective detection of biological and chemical species, Science 293 (5533) (2001) 1289-1292. arXiv:http://www.sciencemag.org/content/293/5533/1289.full. pdf, doi:10.1126/science.1062711.

URL http://www . sciencemag. org/content/293/5533/1289. abstract

[4] E. Stern, J. F. Klemic, D. A. Routenberg, P. N. Wyrembak, D. B. Turner-Evans, A. D. Hamilton, D. A. LaVan, T. M. Fahmy, M. A. Reed, Label-free immunodetection with cmos-compatible semiconducting nanowires, Nature 445 (7127) (2007) 519-522. URL http://dx.doi.org/10.1038/nature05498 
[5] J. Janata, Chemical sensors, Anal. Chem. 64 (12) (1992) R196-R219.

[6] E. J. R. Sudhölter, P. D. van der Wal, M. Skowronska-Ptasinska, A. van den Berg, D. N. Reinhoudt, Ion-sensing using chemically-modified isfets, Sens. Actuators 17 (12) (1989) 189-194.

URL http://doc.utwente.nl/70586/

[7] V. Rocher, N. Jaffrezic-Renault, H. Perrot, Y. Chevalier, P. L. Perchec, Nitratesensitive field-effect transistor with silica gate insulator modified by chemical grafting, Anal. Chim. Acta 256 (2) (1992) 251 - 255. doi:10.1016/0003-2670(92)85351-6. URL http://www.sciencedirect.com/science/article/pii/0003267092853516

[8] D. N. Reinhoudt, J. F. J. Engbersen, Z. Brzozka, H. H. van der Vlekkert, G. W. N. Honig, H. A. J. Holterman, U. H. Verkerk, Development of durable $\mathrm{k}^{+}$-selective chemically modified field effect transistors with functionalized polysiloxane membranes, Anal. Chem. 66 (21) (1994) 3618-3623. arXiv:http://pubs.acs.org/doi/ pdf/10.1021/ac00093a014, doi:10.1021/ac00093a014.

URL http://pubs .acs .org/doi/abs/10.1021/ac00093a014

[9] L. Park, Y. Hur, B. Sohn, Effect of membrane structure on the performance of fieldeffect transistor potassium-sensitive sensor, Sens. Actuators, A 57 (3) (1996) 239-243. doi: $\{10.1016 /$ S0924-4247(97)80120-3\}, 
[10] L. Luo, J. Jie, W. Zhang, Z. He, J. Wang, G. Yuan, W. Zhang, L. C. M. Wu, S.-T. Lee, Silicon nanowire sensors for $\mathrm{hg}^{2+}$ and $\mathrm{cd}^{2+}$ ions, Appl. Phys. Lett. 94 (19) (2009) 193101. doi: $\{10.1063 / 1.3120281\}$.

[11] M. Wipf, R. L. Stoop, A. Tarasov, K. Bedner, W. Fu, I. A. Wright, C. J. Martin, E. C. Constable, M. Calame, C. Schönenberger, Selective sodium sensing with gold-coated silicon nanowire field-effect transistors in a differential setup, ACS Nano 7 (7) (2013) 5978-5983. arXiv:http://pubs.acs.org/doi/pdf/10.1021/nn401678u, doi:10. $1021 / \mathrm{nn} 401678 \mathrm{u}$

URL http://pubs . acs . org/doi/abs/10.1021/nn401678u

[12] A. Gao, N. Lu, Y. Wang, P. Dai, T. Li, X. Gao, Y. Wang, C. Fan, Enhanced sensing of nucleic acids with silicon nanowire field effect transistor biosensors, Nano Lett. 12 (10) (2012) 5262-5268. arXiv:http://pubs.acs.org/doi/pdf/10.1021/ nl302476h, doi:10.1021/nl302476h.

URL http://pubs .acs . org/doi/abs/10.1021/nl302476h

[13] G. Zheng, F. Patolsky, Y. Cui, W. U. Wang, C. M. Lieber, Multiplexed electrical detection of cancer markers with nanowire sensor arrays, Nat. Biotechnol. 23 (10) (2005) 1294-1301.

URL http://dx.doi.org/10.1038/nbt1138 
[14] E. Stern, A. Vacic, N. K. Rajan, J. M. Criscione, J. Park, B. R. Ilic, D. J. Mooney, M. A. Reed, T. M. Fahmy, Label-free biomarker detection from whole blood, Nat. Nanotechnol. 5 (2) (2010) 138-142.

URL http://dx.doi.org/10.1038/nnano.2009.353

[15] N. Elfström, A. E. Karlström, J. Linnros, Silicon nanoribbons for electrical detection of biomolecules, Nano Lett. 8 (3) (2008) 945-949. arXiv:http://pubs.acs.org/ doi/pdf/10.1021/n1080094r, doi:10.1021/n1080094r

URL http://pubs .acs .org/doi/abs/10.1021/nl080094r

[16] X. Duan, Y. Li, N. K. Rajan, D. A. Routenberg, Y. Modis, M. A. Reed, Quantification of the affinities and kinetics of protein interactions using silicon nanowire biosensors, Nat. Nanotechnol. 7 (6) (2012) 401-407.

URL http://dx.doi.org/10.1038/nnano.2012.82

[17] B. Dorvel, B. J. Reddy, R. Bashir, Effect of biointerfacing linker chemistries on the sensitivity of silicon nanowires for protein detection, Anal. Chem. 85 (20) (2013) 9493-9500. arXiv:http://dx.doi.org/10.1021/ac400955f, doi:10.1021/ ac400955f.

URL http://dx.doi.org/10.1021/ac400955f

[18] X. Duan, R. Gao, P. Xie, T. Cohen-Karni, Q. Qing, H. S. Choe, B. Tian, 
X. Jiang, C. M. Lieber, Intracellular recordings of action potentials by an extracellular nanoscale field-effect transistor, Nat. Nanotechnol. 7 (3) (2012) 174-179.

URL http://dx.doi.org/10.1038/nnano.2011.223

[19] O. Knopfmacher, A. Tarasov, W. Fu, M. Wipf, B. Niesen, M. Calame, C. Schönenberger, Nernst limit in dual-gated si-nanowire fet sensors, Nano Lett. 10 (6) (2010) 2268-2274. arXiv:http://pubs.acs.org/doi/pdf/10.1021/ nl100892y, doi:10.1021/nl100892y.

URL http://pubs .acs.org/doi/abs/10.1021/nl100892y

[20] S. Chen, J. G. Bomer, E. T. Carlen, A. van den Berg, $\mathrm{Al}_{2} \mathrm{O}_{3} /$ silicon nanoisfet with near ideal nernstian response, Nano Lett. 11 (6) (2011) 2334-2341. arXiv:http: //pubs.acs.org/doi/pdf/10.1021/nl200623n, doi:10.1021/nl200623n. URL http://pubs .acs . org/doi/abs/10.1021/nl200623n

[21] C. Duarte-Guevara, F.-L. Lai, C.-W. Cheng, B. J. Reddy, E. Salm, V. Swaminathan, Y.-K. Tsui, H. C. Tuan, A. Kalnitsky, Y.-S. Liu, R. Bashir, Enhanced biosensing resolution with foundry fabricated individually addressable dual-gated isfets, Anal. Chem. 86 (16) (2014) 8359-8367. arXiv:http://dx.doi.org/10.1021/ac501912x, doi:10.1021/ac501912x.

URL http://dx.doi.org/10.1021/ac501912x 
[22] J. M. Rothberg, W. Hinz, T. M. Rearick, J. Schultz, W. Mileski, M. Davey, J. H. Leamon, K. Johnson, M. J. Milgrew, M. Edwards, J. Hoon, J. F. Simons, D. Marran, J. W. Myers, J. F. Davidson, A. Branting, J. R. Nobile, B. P. Puc, D. Light, T. A. Clark, M. Huber, J. T. Branciforte, I. B. Stoner, S. E. Cawley, M. Lyons, Y. Fu, N. Homer, M. Sedova, X. Miao, B. Reed, J. Sabina, E. Feierstein, M. Schorn, M. Alanjary, E. Dimalanta, D. Dressman, R. Kasinskas, T. Sokolsky, J. A. Fidanza, E. Namsaraev, K. J. McKernan, A. Williams, G. T. Roth, J. Bustillo, An integrated semiconductor device enabling non-optical genome sequencing, Nature 475 (7356) (2011) 348-352.

URL http://dx.doi.org/10.1038/nature10242

[23] D. E. Yates, S. Levine, T. W. Healy, Site-binding model of the electrical double layer at the oxide/water interface, J. Chem. Soc., Faraday Trans. 70 (1974) 1807-1818. doi:10.1039/F19747001807.

URL http://dx.doi.org/10.1039/F19747001807

[24] T. W. Healy, L. R. White, Ionizable surface group models of aqueous interfaces, Adv. Colloid Interface Sci. 9 (4) (1978) 303 - 345. doi:10.1016/0001-8686(78)85002-7. URL http://www.sciencedirect.com/science/article/pii/0001868678850027

[25] R. Schasfoort, P. Bergveld, R. Kooyman, J. Greve, Possibilities and limitations of 
direct detection of protein charges by means of an immunological field-effect transistor, Anal. Chim. Acta 238 (1990) 323-329.

URL http://doc.utwente.nl/72860/

[26] P. Bergveld, A critical evaluation of direct electrical protein detection methods, Biosens. Bioelectron. 6 (1) (1991) 55 - 72. doi:10.1016/0956-5663(91)85009-L. URL http://wWw.sciencedirect.com/science/article/pii/095656639185009L

[27] L. Meixner, S. Koch, Simulation of isfet operation based on the site-binding model, Sens. Actuators, B 6 (13) (1992) 315 - 318. doi:http://dx.doi.org/10.1016/ 0925-4005(92) 80077-B.

URL http://www.sciencedirect.com/science/article/pii/092540059280077B

[28] P. T. Mcbride, J. Janata, P. A. Comte, S. D. Moss, C. C. Johnson, Ion-selective field effect transistors with polymeric membranes, Anal. Chim. Acta 101 (2) (1978) 239 - 245. doi:http://dx.doi.org/10.1016/S0003-2670(01)93360-4.

URL http://www.sciencedirect.com/science/article/pii/ S0003267001933604

[29] A. Tarasov, M. Wipf, K. Bedner, J. Kurz, W. Fu, V. A. Guzenko, O. Knopfmacher, R. L. Stoop, M. Calame, C. Schönenberger, True reference nanosensor realized with silicon nanowires, Langmuir 28 (25) (2012) 9899-9905. arXiv:http://pubs.acs. 
org/doi/pdf/10.1021/la301555r, doi:10.1021/la301555r.

URL http://pubs .acs .org/doi/abs/10.1021/la301555r

[30] B. K. Wunderlich, P. A. Neff, A. R. Bausch, Mechanism and sensitivity of the intrinsic charge detection of biomolecular interactions by field effect devices, Appl. Phys.

Lett. 91 (8) (2007) 083904. doi:http://dx.doi.org/10.1063/1.2775040.

URL http://scitation.aip.org/content/aip/journal/apl/91/8/10.1063/1. 2775040

[31] A. Tarasov, W. Fu, O. Knopfmacher, J. Brunner, M. Calame, C. Schönenberger, Signal-to-noise ratio in dual-gated silicon nanoribbon field-effect sensors, Appl. Phys.

Lett. 98 (1) (2011) 012114. doi:10.1063/1.3536674.

URL http://link.aip.org/link/?APL/98/012114/1

[32] K. Bedner, V. A. Guzenko, A. Tarasov, M. Wipf, R. L. Stoop, S. Rigante, J. Brunner, W. Fu, C. David, M. Calame, J. Gobrecht, C. Schönenberger, Investigation of the dominant 1/f noise source in silicon nanowire sensors, Sens. Actuators, B 191 (0) (2014) 270 - 275. doi:http://dx.doi.org/10.1016/j.snb.2013.09.112.

URL http://www.sciencedirect.com/science/article/pii/ S0925400513011659

[33] K. Bedner, V. A. Guzenko, A. Tarasov, M. Wipf, R. L. Stoop, D. Just, S. Rigante, 
W. Fu, R. A. Minamisawa, C. David, M. Calame, J. Gobrecht, C. Schönenberger, ph response of silicon nanowire sensors: Impact of nanowire width and gate oxide, Sens. Mater. 25 (8) (2013) 567-576.

URL http://www .myu-inc.jp/myukk/S\&M/paper4.html

[34] J. R. Sandifer, Theory of interfacial potential differences: effects of adsorption onto hydrated (gel) and nonhydrated surfaces, Anal. Chem. 60 (15) (1988) 1553-1562. arXiv:http://dx.doi.org/10.1021/ac00166a016, doi:10.1021/ac00166a016. URL http://dx.doi.org/10.1021/ac00166a016

[35] J. Janata, R. J. Huber (Eds.), Solid State Chemical Sensors, Academic Press, INC., 1985.

[36] J. Janata, Electrochemistry of chemically sensitive field effect transistors, Sensors and Actuators 4 (0) (1983) 255 - 265. doi:http://dx.doi.org/10.1016/ 0250-6874(83)85031-8. URL http://www.sciencedirect.com/science/article/pii/0250687483850318

[37] L. Bousse, N. De Rooij, P. Bergveld, Operation of chemically sensitive field-effect sensors as a function of the insulator-electrolyte interface, IEEE Trans. Electron Devices 30 (10) (1983) 1263-1270. doi:10.1109/T-ED.1983.21284. 
[38] A. Watts (Ed.), Protein-Lipid Interactions, Elsevier: Amsterdam, 1993.

[39] R. Williams, pka data compiled by r. williams ((accessed September 2, 2014)). URL http://research.chem.psu.edu/brpgroup/pKa_compilation.pdf

[40] V. Bagotsky, Fundamentals of Electrochemistry, The ECS Series of Texts and Monographs, John Wiley \& Sons: Hoboken, 2005.

URL http://books.google.ch/books?id=09QI-assq1cC

[41] A. Tarasov, M. Wipf, R. L. Stoop, K. Bedner, W. Fu, V. A. Guzenko, O. Knopfmacher, M. Calame, C. Schönenberger, Understanding the electrolyte background for biochemical sensing with ion-sensitive field-effect transistors, ACS Nano 6 (10) (2012) 9291-9298. arXiv:http://pubs.acs.org/doi/pdf/10.1021/nn303795r, doi:10. $1021 / \mathrm{nn} 303795 \mathrm{r}$.

URL http://pubs .acs .org/doi/abs/10.1021/nn303795r

[42] R. Y. Tsien, New calcium indicators and buffers with high selectivity against magnesium and protons: Design, synthesis, and properties of prototype structures, Biochemistry 19 (11) (1980) 2396-2404. arXiv:http://pubs.acs.org/doi/pdf/10. 1021/bi00552a018, doi:10.1021/bi00552a018.

URL http://pubs .acs .org/doi/abs/10.1021/bi00552a018 
[43] R. B. Schasfoort, W. de Lau, A. van der Kooi, H. Clevers, G. H. Engbers, Method for estimating the single molecular affinity, Anal. Biochem. 421 (2) (2012) $794-$ 796. doi:http://dx.doi.org/10.1016/j.ab.2011.12.011.

URL http://www.sciencedirect.com/science/article/pii/ S0003269711007822

\section{Biographies}

Ralph L. Stoop is a PhD student in the Nanoelectronics group of Prof. Christian Schönenberger at the University of Basel. He received his M.S. degree in electrical engineering and information technology at the Swiss Federal Institute of Technology, Zurich, in 2011. His PhD work focuses on ion sensitive field effect transistors for chemical sensing applications.

Mathias Wipf received his PhD in Physics in 2014 in the Nanoelectronics group of Prof. Christian Schönenberger and Michel Calame at the University of Basel. He received his M.S. degree in Nanoscience at the University of Basel in 2010. His field of research is the development of a biosensor based on the principle of ion sensitive field effect transistors. Steffen Müller received his Ph.D. degree in Chemistry at the University of Basel, Switzerland in 2014. Research topic of his thesis was the synthesis of organic ligands and transition metals coordination complexes for surface functionalization and sensing 
applications. He is now working as a postdoc at the Department of Chemistry, University of Basel.

Kristine Bedner received her PhD degree at the Laboratory for Micro- and Nanotechnology of the Paul Scherrer Institut, Switzerland. Her PhD work was focused on the fabrication and characterization of bio-/chemical nanowire sensors.

Iain A. Wright obtained his PhD in chemistry in 2011 from the University of Strathclyde in Glasgow, Scotland working on oligothiophene based molecules for organic photovoltaics and field effect transistors. He then moved to the University of Basel as a postdoctoral research associate in the group of Prof. Edwin Constable and Prof. Catherine Housecroft where his work focused primarily on the synthesis of ion sensitive small molecules for chemical sensors.

Colin J.Martin received his Ph.D. from the School of Chemistry, Trinity College Dublin in 2010 for research into supramolecular derivatives of polyphenylenes. He then moved to a postdoctoral positon within the Department of Inorganic Chemistry, University of Basel. His recent research is focused on the production of new copper based photosensitizers along with the development of scanning electrochemical microscopy as a tool for the surface examination of dye sensitized solar cells.

Edwin Constable is a full professor of chemistry and Vice-Rector of the University of Basel. He currently holds and ERC Advanced Grant centred on his primary research 
interests of developing a sustainable materials chemistry for energy related topics. He was elected as one of the Global Thinkers of 2014.

Wangyang Fu received his PhD degree at the Institute of Physics, Chinese Academy of Sciences in 2009 for research activities in integrating ferroelectrics into nanoscale transistors. He is now working as a postdoc at the Department of Physics, Universityof Basel. His recent research is focused on the applications of silicon nanowire and graphene as Bio/Chemical sensors.

Alexey Tarasov received his diploma in physics from the University of Düsseldorf, Germany, in 2009. In the same year he joined the Nanoelectronics Group at the University of Basel to pursue his $\mathrm{PhD}$ degree in the field of chemical sensing with silicon nanowire fieldeffect transistors. After graduating in 2012, he received a postdoctoral fellowship from the Swiss National Science Foundation and moved to the School of Materials Science and Engineering at the Georgia Institute of Technology, Atlanta, GA, USA. His current research deals with large-area two-dimensional semiconductors for flexible electronics and sensing applications.

Michel Calame after receiving his $\mathrm{PhD}$ in condensed matter physics from the University of Neuchtel (CH) in 1998, moved to the Center for Studies in Physics and Biology at the Rockefeller University (NY, USA) thanks to a grant from the Swiss National Science Foundation. In 2001, he joined the nanoelectronics group of Prof.C. Schönenberger at the 
University of Basel (CH). He is currently a lecturer (privat-docent) at the Department of Physics, University of Basel and his research focuses on the (opto-)electrical properties of nanometer-scale structures with a particular emphasis on molecular devices.

Christian Schönenberger is a full professor in experimental condensed matter physics. He is the director of the Swiss Nanoscience Institute and groupleader of the nanoelectronics group at the Department of Physics of the University of Basel. His research focus is in electrical properties of nano-sized hybrid devices realized using carbon nanotubes, semiconducting nanowires and graphene.

\section{Figures Caption}

Figure 1: (a) General model of two competing surface reactions coupled only via the surface potential $\Psi_{0}$. The measurement of the target analyte $\mathrm{A}_{1}^{+}$suffers from the competing reaction involving analyte $\mathrm{A}_{2}^{+}$. The parameters describing this system are the dissociation constants $K_{1}, K_{2}$ and the number of surface sites $N_{1}$ and $N_{2}$. (b) Surface potential $\Psi_{0}$ versus the bulk activities $a_{1}$ and $a_{2}$ calculated using the general model with $K_{1}=10^{-5} \mathrm{M}, K_{2}=10^{-8} \mathrm{M}, N_{1}=0.8 \cdot 10^{17} \mathrm{~m}^{-2}$ and $N_{2}=1.1 \cdot 10^{17} \mathrm{~m}^{-2}$. (c) Surface potential $\Psi_{0}$ versus activity $a_{1}$ of target $\mathrm{A}_{1}^{+}$for different $N_{2}\left(N_{2}=1.1 \cdot 10^{17} \mathrm{~m}^{-2}\right.$ is highlighted by the thick line). The activity $a_{2}=1 \cdot 10^{-7} \mathrm{M}$ is set constant. Increasing $N_{2}$ decreases the response of the sensor towards the targeted analyte $\mathrm{A}_{1}^{+}$. Furthermore, the 
range of activity, where the analyte can be detected, shifts towards higher $a_{1}$ for more positive surface potential. (d) Surface potential $\Psi_{0}$ versus activity $a_{2}$ of the competing species $\mathrm{A}_{2}^{+}$for different $N_{2}\left(N_{2}=1.1 \cdot 10^{17} \mathrm{~m}^{-2}\right.$ is highlighted by the thick line $)$. The activity $a_{1}=10^{-15} \mathrm{M}$ is set constant.

Figure 2: (a) Schematics of a specific realization of the sensing model with $\mathrm{pH}$ as competing surface reaction. The gold surface of the sensor is functionalized using calciumsensitive molecules ('Ligand'). The total number of molecules is given by $N_{\text {Ligand }}$. The functionalization results in two surface groups, namely Ligand $\left(\mathrm{Ca}^{2+}\right)$ and $\operatorname{Ligand}()$ for the molecule bound/unbound to the target. Besides these two groups due to the functionalization, additional hydroxyl groups are present, being subject to protonation and deprotonation. The total number of hydroxyl groups is given by $N_{s}$ consisting of negatively charged $\mathrm{O}^{-}$, positively charged $\mathrm{OH}_{2}^{+}$as well as neutral $\mathrm{OH}$ groups. The reaction of these surface groups with protons and calcium ions of the solution builds up a surface potential $\Psi_{0}$. In this setup, a liquid-gate voltage $V_{\text {ref }}$ is applied at the reference electrode. A constant source-drain voltage $V_{s d}=100 \mathrm{mV}$ is applied and the source-drain current $I_{s d}$ through the nanoribbon is measured. (b) Threshold voltage $V_{t h}$ versus $\mathrm{pH}$ of a functionalized nanoribbon (active) and a bare gold nanoribbon (control). The threshold voltage $V_{t h}$ has been extracted from the transfer characteristics of the nanoribbon ISFET as exem- 
plified in the inset. The inset shows the conductance $G$ versus liquid gate potential $V_{\text {ref }}$ for the active nanoribbon measured in different $\mathrm{pH}$ solutions. We read out the threshold voltage $V_{\text {th }}$ as a value of $V_{\text {ref }}$ at a constant conductance value $G=20 \mathrm{nS}$ as indicated by the red arrow. (c-e) Threshold voltage $V_{t h}$ versus activity of $\mathrm{CaCl}_{2}$ of the same pair of active and control nanoribbon as shown in (b), measured at different $\mathrm{pH}$ values.

Figure 3: (a) Surface potential $\Psi_{0}$ versus $\mathrm{pH}$ with theoretical lines for different parameters (dashed lines) and the actual $\mathrm{pH}$ measurement of three control nanoribbons (solid symbols). The measured threshold voltage $V_{t h}$ of each nanoribbon is converted to the surface potential as explained in the text. We find that a $p K_{a}=8$ and $p K_{b}=6$ and $N_{s}=1.1 \cdot 10^{17} \mathrm{~m}^{-2}$ (solid line) gives good agreement with the data. (b) Surface potential $\Psi_{0}$ versus the activity of calcium ions of the electrolyte with theoretical fits (solid lines) and the sensor response (solid dots). The sensor response $\Delta V_{t h}$ has been converted to the surface potential as explained in the text. From the fits we find $K_{\text {Ligand }}=50 \mathrm{mM}$ and $N_{\text {Ligand }}=0.6 \cdot 10^{17} \mathrm{~m}^{-2}$. (c) Theoretical plots of the surface potential $\Psi_{0}$ versus activity $a_{\mathrm{Ca}^{2+}}$ and $\mathrm{pH}$ with $K_{a, b}$ and $N_{s}$ obtained from the $\mathrm{pH}$ measurement. $N_{\text {Ligand }}, K_{\text {Ligand }}$ were then determined from the actual measurements performed at $\mathrm{pH}$ 3, $\mathrm{pH} 7$ and $\mathrm{pH} 10$ (solid lines in the graph). 
(a) Target Competing reaction

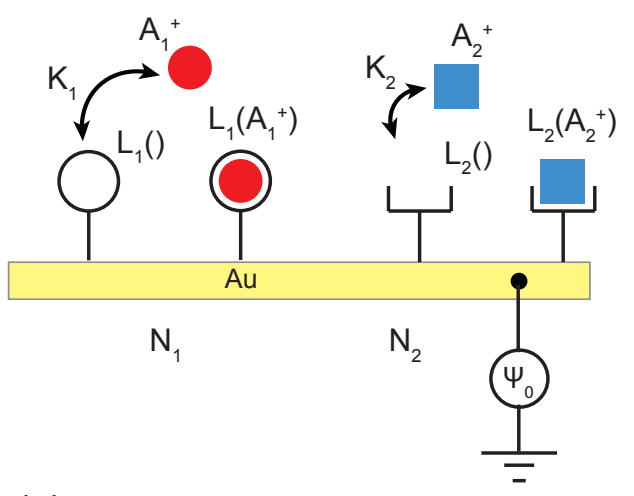

(c)

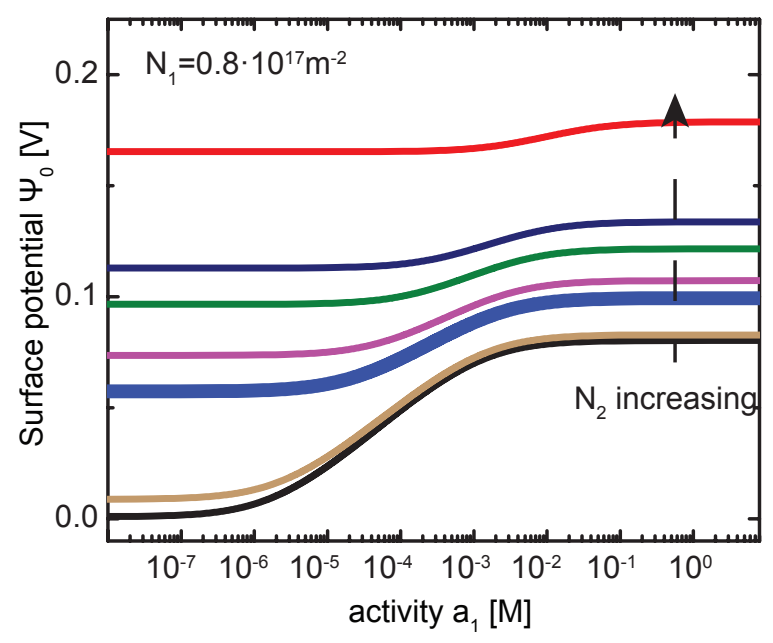

(b) $K_{1}=10^{-5} \mathrm{M}$

$$
\mathrm{K}_{2}=10^{-8} \mathrm{M}
$$

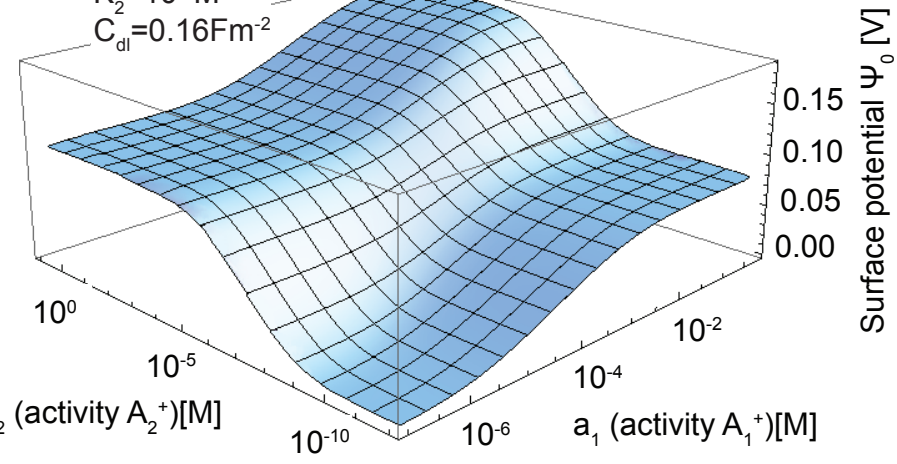

(d)

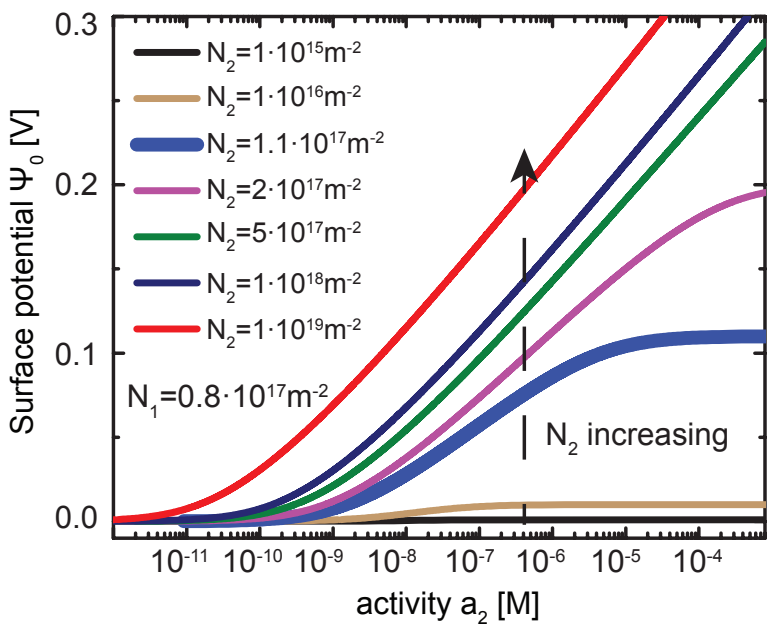

Figure 1: 


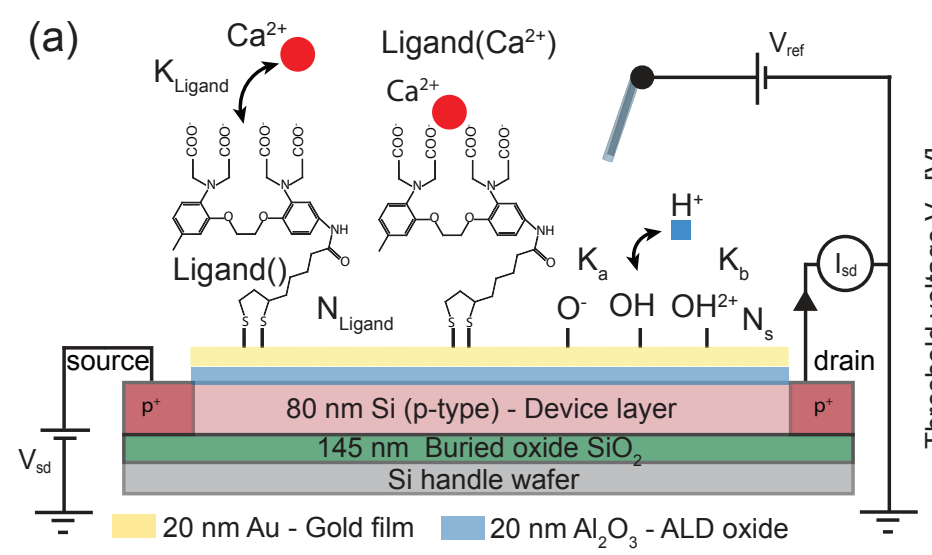

(c)

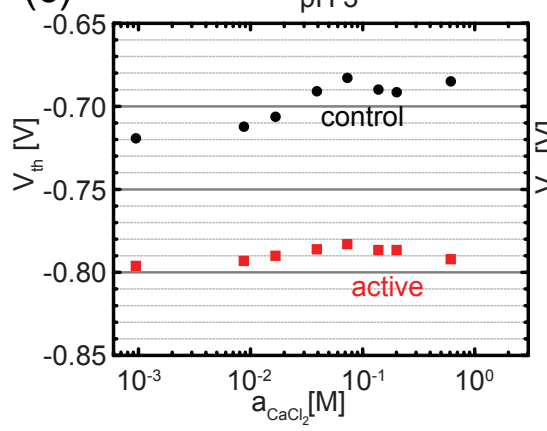

(d)

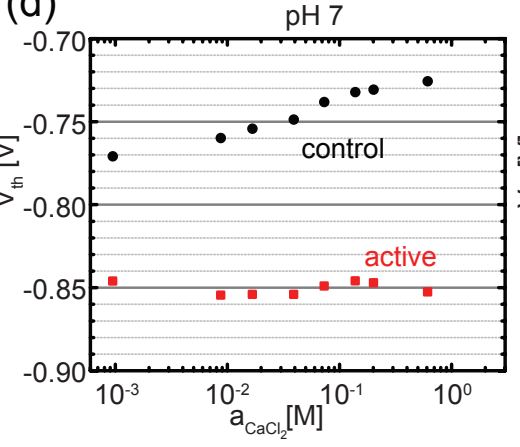

(b)

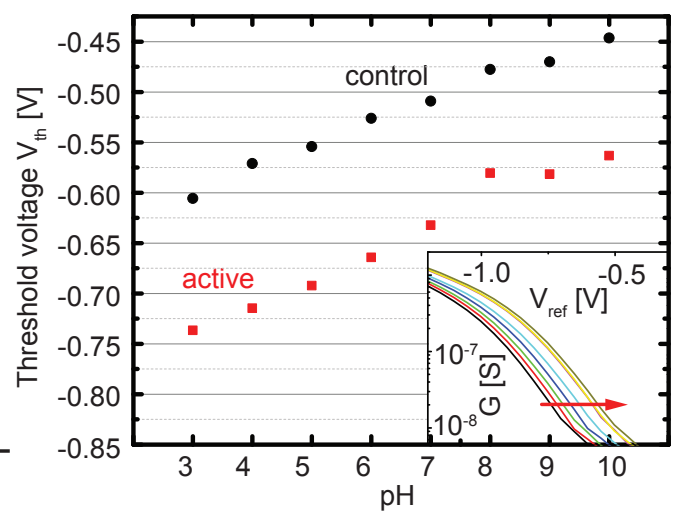

(e)

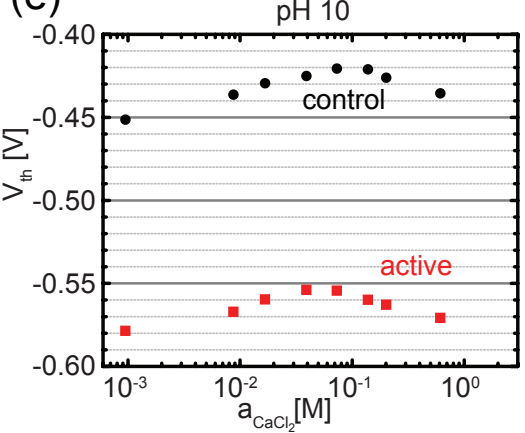

Figure 2: 

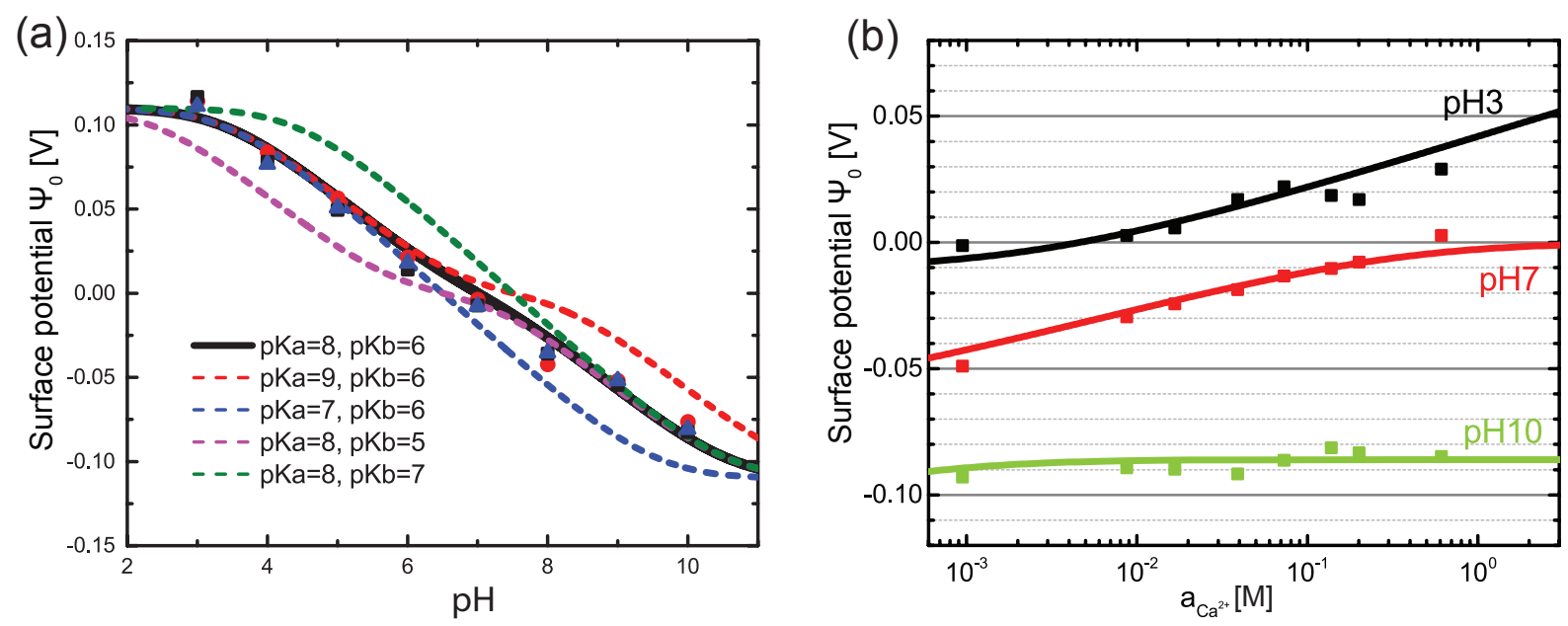

(c) $\begin{aligned} & \mathrm{N}_{\mathrm{s}}=1 \cdot 1 \cdot 10^{17} \mathrm{~m}^{-2} \\ & \mathrm{~N}_{\text {Ligand }}=0.6 \cdot 10^{17} \mathrm{~m}^{-2}\end{aligned}$

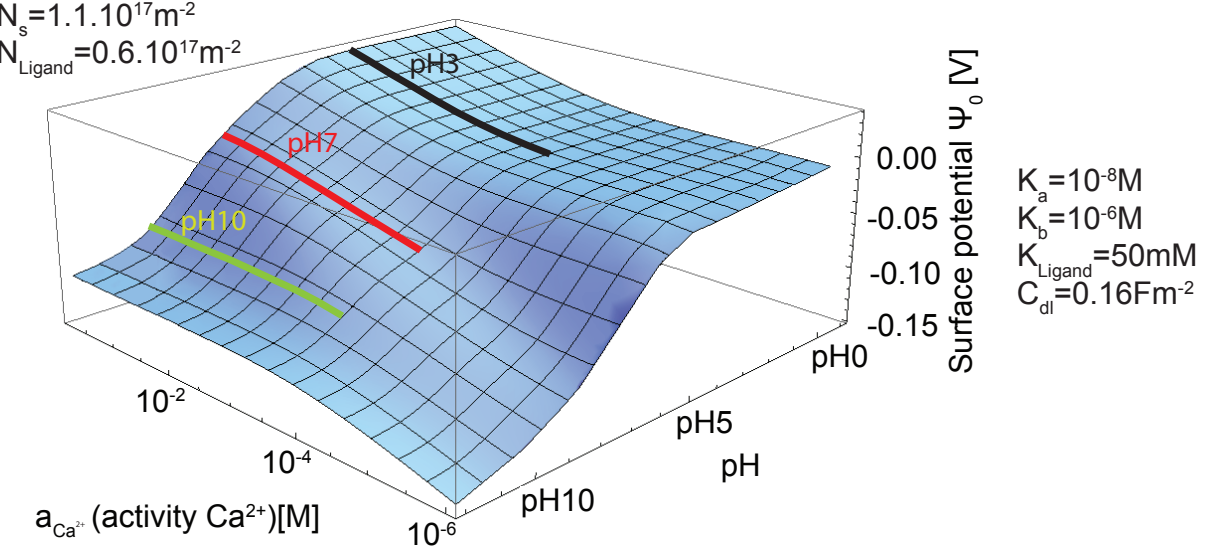

Figure 3: 